\title{
Di(2-ethylhexyl) adipate (DEHA) detection in Antarctic krill (Euphasia superba Dana)
}

\author{
Xiangning Han \& Daicheng Liu \\ Key Laboratory of Animal Resistance, College of Life Science, Shandong Normal University, Jinan, P. R. China
}

\begin{abstract}
In this reported study, a novel high-performance thin-layer chromatography (HPTLC) method was developed for the detection and quantification of the toxic substance di(2-ethylhexyl) adipate (DEHA) in Antarctic krill. This procedure was based on the extraction of DEHA by ultrasonic solvent extraction with anhydrous ethanol, silica-gel column chromatographic separation, HPTLC detection and quantification using petroleum ether/ethyl acetate/ acetone/glacial acetic acid (29:1:0.5:2 $\left.\mathrm{d}^{*}, \mathrm{v} / \mathrm{v} / \mathrm{v} / \mathrm{v}\right)$ as the developing solvent and bromine thymol blue solution as the chromogenic agent. The content of DEHA in freeze-dried Antarctic krill was found to be ca. $0.63 \pm 0.05 \mathrm{mg} / \mathrm{g}$. The structure of DEHA in the Antarctic krill was subsequently determined by gas chromatography-mass spectrometry (GC-MS) and infrared chromatography, which verified the presence of this compound in the krill. The HPTLC method exhibited excellent accuracy, with a recovery of $97.1-101.6 \%$ and good precision with a relative standard deviation of $2.47-4.90 \%$. The DEHA in Antarctic krill oil was extracted by $n$-hexane and detected using the same method described above, which verified that DEHA was also present in krill oil at a concentration of ca. $2.16 \pm 0.08 \mathrm{mg} / \mathrm{g}$. The presence of DEHA in kill oil is very concerning because of its demonstrated harmful ecotoxicity, and since Antarctic krill is the key link in the food chain in the Antarctic coastal marine ecosystem. The adverse effects of DEHA on Antarctic krill and the source of DEHA will be explored in future research.
\end{abstract}

\section{KEYWORDS}

toxicity; high-performance thin-layer chromatography (HPTLC); ecotoxins; plastic particles; marine pollution; krill oil

\section{ABBREVIATIONS}

2d: two drops; $A U$ : absorbance unit; DEHA: di(2-ethylhexyl) adipate; FTIR: Fourier-transform infrared spectroscopy; GC-MS: gas chromatography-mass spectrometry; HPLC:

high-performance liquid chromatography; HPTLC: high performance thin-layer chromatography; IR: infrared chromatography; RSD: relative standard deviation; SD: standard deviation; TLC: thin-layer chromatography

\section{Introduction}

DEHA is a suitable substitute for di(2-ethylhexyl) phthalate in some applications (Felder et al. 1986). This compound has been widely used in the plastics industry and other fields on account of its high boiling point, good electrical properties, good weathering resistance and good thermal and light stability (Abdul Rahman et al. 2009). It is primarily used as a plasticizer in food wraps, vinyl blood bags and haemodialysis bags (Yavan 1984). It is also added into plastic toys and other toys for children (Rahman \& Brazel 2004). DEHA has been a component of cosmetic bases and solvents and it also has been widely used in the aerospace and automotive industries, as well as under extreme working conditions, such as high-temperature environments, on account of its high thermal-oxidation stability, large specific heat capacity, good stickiness index and excellent thermal conductivity (Yavan 1984; Qian et al. 2016). DEHA has been shown to migrate when packaging material is in direct contact with high fat content foods, which can lead to high DEHA concentration and contamination of the food (Badeka et al. 1999). DEHA can be released into the environment during its synthesis and distribution and in consumer use of finished plastic products (Felder et al. 1986).

DEHA seriously inhibits the survival and growth of algae and the planktonic crustacean Daphnia magna at very low concentration (Felder et al. 1986; Bi et al. 2016). DEHA can induce remarkable histopathological changes in gill tissue and can produce hepatocellular changes in various species of fishes (Üçüncü et al. 2010; Üreten \& Üçüncü 2013). It has been reported that DEHA seriously damaged the liver of rats and mice by affecting lipid metabolism, causing liver tumours and inducing DNA damage, among other negative effects (Bell 1983; Takagi et al. 1990; Lake et al. 1997; Dalgaard et al. 2003). Studies have found that DEHA can produce reproductive and developmental toxicity by interfering with the estrous cycle and increasing ovarian follicle atresia; it was found to be harmful to both the mother and foetus (Miyata et al. 2006). DEHA has caused adrenal weight decrease in adult male rats (Miyata et al. 2006). All of these results strongly suggest that the toxicity of DEHA, particularly its ecotoxicity, should 
receive great attention. Unfortunately, there is little available scientific data on the concentration of DEHA in Antarctic krill.

Antarctic krill (Euphausia superba), a marine planktonic crustacean that lives in schools, is the key component of the food webs in the Antarctic coastal marine ecosystem (Kokubun et al. 2015). This abundant species comprises an estimated biomass of 400-1550 million metric tonnes, which may be the largest biomass of any multicellular species on the planet (Gigliotti et al. 2011). Antarctic krill contains high-quality lipids, and krill oil contains high levels of omega-3 polyunsaturated fatty acids (n-3 PUFA) such as eicosapentaenoic (EPA, 20:5n3) and docosahexaenoic (DHA, 22:6n3), which are easily absorbed by humans (Gigliotti et al. 2011; Ali-Nehari et al. 2012). The content of antioxidant astaxanthin in Antarctic krill is extremely high; astaxanthin can effectively scavenge oxygen free radicals in the body (Ali-Nehari et al. 2012). The lipids in Antarctic krill are beneficial to health in the areas of obesity, coronary heart disease, inflammation and brain function, among others (Maki et al. 2009; Fosshaug et al. 2011; Wibrand et al. 2013). These features, together with others, make Antarctic krill an outstanding food source and medical resource.

Methods for detecting DEHA have been presented in numerous reports. For instance, Di Bella et al. (2014) determined DEHA residues in moka pots, coffee pods and coffee capsules made from polypropylene and in polypropylene with a micro-perforated film of low-density polyethylene lids by GC-MS. Lo Turco et al. (2015) studied plasticizer residues in tea by solid phase extraction-GC-MS. Fromme et al. (2013) used a GC-MS method to study the daily intake of DEHA by infants through their standard diet by sampling for detection of DEHA in urine and proved that GC-MS was an excellent analytical method with good accuracy and high sensitivity. Wang detected DEHA in mixed plasticizer by HPLC (Wang 1996).

Although there is a wide choice of chromatographic methods for plasticizer analysis (GC, HPLC), the technology of HPTLC has gained greater acceptance as an analytical procedure because of its low operation cost and high sample throughput in recent years (Rezić et al. 2005; He et al. 2013; Li et al. 2016). As there has been no detailed HPTLC detection method for DEHA for krill and similar animals, the aim of the present study was to detect the presence of DEHA in Antarctic krill using an HPTLC detection method, determine its quantity and discuss its potential harmful effects.

\section{Materials and methods}

\section{Sample, reagents and instrumentation}

Frozen whole Antarctic krill were purchased from the Liaoning Fishery Group (Dalian, Liaoning, China). The batch of Antarctic krill used in this study (35-55 mm in body length) was caught in the first quarter of 2015 from the waters surrounding the Chinese Great Wall Antarctic Station (48.1-48.3 zone in the Antarctic). A DEHA standard ( $\geq 99 \%)$ was obtained from Aladdin Chemical (Shanghai, China). All the other reagents used in this study were analytically pure. An FUD1200 freeze-dryer was obtained from Tokyo Rikakikai Co., Ltd (Tokyo, Japan). The ultrasonic cleaning device used in this study was purchased from Kun Shan Ultrasonic Instruments Co., Ltd (Jiangsu, China). A rotavapor-3 rotating evaporator was obtained from Buchi (Flawil, Switzerland). A silica gel chromatography column $(3 \times 60 \mathrm{~cm})$ was obtained from Shandong Research Institute of Chemical Industries (Shandong, China). Pre-coated silica gel $\mathrm{GF}_{254}$ high-performance TLC plates $\left(10 \times 10 \mathrm{~cm}^{2}\right)$ and silica gel (200-300 mesh) were purchased from Haiyang Chemical (Qingdao, Shandong, China). A chromatography development chamber $\left(10 \times 12 \times 5 \mathrm{~cm}^{3}\right.$, consisting of a twin trough glass chamber) was obtained from Shanghai Xinyi Instrument Co., Ltd (Shanghai, China). A TLC Scanner 3 equipped with the Wincats 1.4.1 software was purchased from CAMAG (Muttenz, Switzerland). The Fourier transform infrared spectrometer used for this study (Bruker Tensor II) was purchased from Bruker Instruments (Karlsruhe, Germany). None of the experimental instruments and materials was composed of plastic to avoid any hint of contamination.

\section{Preparation of sample solution and standard solution}

Krill samples (ca. $200 \mathrm{~g}$ ) were cut from the middle section of a chunk of frozen krill - to avoid sampling krill in contact with the plastic packaging - and were freeze-dried at $-46^{\circ} \mathrm{C}$ to produce $40 \mathrm{~g}$ of dry Antarctic krill. This dry Antarctic krill sample was extracted three times with anhydrous ethanol $(1: 15, \mathrm{w} / \mathrm{v})$ using ultrasound for $0.5 \mathrm{~h}$, at $35^{\circ} \mathrm{C}, 350 \mathrm{w}, 40 \mathrm{kHz}$. The extracts were combined, filtered (after flushing with anhydrous ethanol) and evaporated to dryness $\left(50^{\circ} \mathrm{C}\right)$. The residue was dissolved in anhydrous ethanol and the volume of the mixture was accurately set to $10 \mathrm{ml}$ in a volumetric flask. This original DEHA sample (Sample A) was used for analysis and refinement.

Standard solutions of DEHA were prepared by dissolving accurate quantities of DEHA $(\geq 99.5 \%)$ in methanol. The mass concentration of DEHA was $1.0 \mathrm{mg} / \mathrm{ml}$.

\section{Verifying the presence of DEHA and refining the original sample}

The developing solvent petroleum ether/ethyl acetate/ acetone/glacial acetic acid (29:1:0.5:2d, v/v/v/v) was added to the development chamber and incubated for $30 \mathrm{~min}$ in a fume hood. The $3 \mu \mathrm{L}$ Sample A, DEHA 
standard and blank solution (anhydrous ethanol solution, the DEHA extraction solution from Antarctic krill) were respectively spotted onto the same activated pre-coated silica gel HPTLC $\mathrm{GF}_{254}$ plate $\left(10 \times 10 \mathrm{~cm}^{2}\right)$. The plate was developed, air dried, dipped into a solution of bromine thymol blue for $15 \mathrm{~s}$, removed and then dried at room temperature. A CAMAG TLC scanner 3 with Wincats 1.4.1 software was used to analyse the plate at the reflectance-absorbance wavelength of $400 \mathrm{~nm}$ using a tungsten lamp. The scanning speed was $20 \mathrm{~mm} / \mathrm{s}$ and the data resolution was a $50 \mu \mathrm{m} / \mathrm{step}$.

Activated silica gel (90 g, 200-300 meshes) was mixed with methylene chloride $(1: 2, \mathrm{w} / \mathrm{v})$ and poured into a chromatography column $(3.0 \times 60 \mathrm{~cm}) .1 \mathrm{ml}$ of the Sample A was applied to the column and eluted with methylene chloride /methanol (8:1, v/v). The $100 \mathrm{ml}$ fractions of the eluent were collected and tentative identification was conducted using the HPTLC method described above. The fractions containing DEHA were pooled and dried by rotary evaporation. The residue was weighed and brought to a precise volume of $5 \mathrm{ml}$ with methanol and then used for GC-MS and IR analysis and quantification (Sample B).

\section{Quantifying DEHA in Antarctic krill}

Select quantities $(1 \mu \mathrm{l}, 2 \mu \mathrm{l}, 3 \mu \mathrm{l}, 3.5 \mu \mathrm{l}, 4 \mu \mathrm{l})$ of DEHA standard solutions were spotted on the same $\mathrm{GF}_{254}$ HPTLC plate, which contained $1 \mu \mathrm{g}, 2 \mu \mathrm{g}, 3 \mu \mathrm{g}, 3.5 \mu \mathrm{g}$ and $4 \mu \mathrm{g}$ of DEHA. Then $3 \mu \mathrm{l}$ of Sample B was spotted on this same plate. This plate was then developed using the previously described HPTLC process, spots with peak areas were analysed using the Wincats 1.4.1 software to determine linearity of DEHA detection and to obtain the concentration of DEHA in Sample B. The DEHA concentration in the Antarctic krill was then calculated.

\section{Validating the HPTLC method}

\section{Intraplate variation and interplate variation}

To determine if there was any variation in the detection of DEHA, $2 \mu \mathrm{l}$ of the DEHA standard solution was spotted on one $\mathrm{GF}_{254}$ HPTLC plate in five repetitive spots; this plate was developed using the previously detailed mentioned to determine the relative intraplate variation in the DEHA detection. The peak area data were recorded and analysed using Wincats software. To evaluate the interplate variation, the same volume of DEHA standard solution $(2 \mu \mathrm{L})$ was spotted on five individual $\mathrm{GF}_{254}$ HPTLC plates. These plates were developed in the usual manner and the peak area data were recorded and analysed.

\section{Stability}

To determine the stability of the chromogen in the analysis, $2.5 \mu \mathrm{L}$ of the DEHA standard solution was spotted on one $\mathrm{GF}_{254}$ HPTLC plate in three replicate spots. After the plate was developed, it was scanned 1, 2 and $3 \mathrm{~h}$ after generating the chromogen and the peak areas were analysed using the scanning software.

\section{Limit of detection and limit of quantification}

The limit of detection and the limit of quantification were determined by serially diluting the DEHA standard solution. The limit of detection was defined as the amounts of DEHA that produced a 3:1 signal-to-noise ratio and the limit of quantification was defined as the amount of DEHA that produced a 10:1 signal-to-noise.

\section{Extracting and detecting DEHA in Antarctic krill oil}

An Antarctic krill oil sample was prepared using the method described above, but employing $n$-hexane as the extraction solvent. The purification and detection of DEHA in Antarctic krill oil were performed using the method and conditions described above.

\section{Detection DEHA Sample B by GC-MS}

The DEHA in Sample B was detected using an Agilent7890 GC-MS with an Agilent DB-1 ms (G3900-63017) chromatographic column (size: $30 \mathrm{~m}, 0.25 \mathrm{~mm}$, $0.25 \mu \mathrm{m}$ ) employing the following conditions. The column temperature was initially set to $100^{\circ} \mathrm{C}$ and maintained for $4 \mathrm{~min}$, then it was gradually increased to $120^{\circ}$ $\mathrm{C}$ at $50^{\circ} \mathrm{C} / \mathrm{min}$ and maintained for $10 \mathrm{~min}$. The column temperature was then increased to $220^{\circ} \mathrm{C}$ at $50^{\circ} \mathrm{C} / \mathrm{min}$ and maintained for $6 \mathrm{~min}$. The injector and detector temperatures were set at $200^{\circ} \mathrm{C}$ and $250^{\circ} \mathrm{C}$. The ionization mode had an electron impact ion source; the four stage rod temperature was $150^{\circ} \mathrm{C}$ and the ion power temperature was $230^{\circ} \mathrm{C}$. The monitoring mode was full scanned (50-550 amu units) in the selective ion scanning mode. For GC-MS detection, an electron ionization system was used with an ionization energy of $70 \mathrm{eV}$, and the solvent delay was $2 \mathrm{~min}$.

\section{Detection DEHA Sample B by IR}

IR spectroscopy was conducted on Sample B to determine the structure of the DEHA in the sample. For this work a Fourier transform infrared spectrometer (Bruker Tensor II) was used with a resolution ratio of $4 \mathrm{~cm}^{-1}$. The background and the sample were each scanned 16 times and the range of determination was $4000-400 \mathrm{~cm}^{-1}$. 


\section{Repetition and recovery}

Eight 40-g samples of Antarctic krill were extracted, refined and quantified as described. The accuracy of the method was evaluated by a recovery test with three different DEHA concentrations. To accomplish this, three standard solutions of DEHA (1.25 mg, $2.5 \mathrm{mg}, 3.75 \mathrm{mg}$ ) were individually added to three $1 \mathrm{ml}$ aliquots of Sample A (DEHA concentration $2.5 \mathrm{mg} / \mathrm{ml}$ ). After refining the solutions using silica gel column chromatography, the resulting combined eluents were spotted on a HPTLC plate in triplicate. Chromatograms were developed and scanned as previously described. The results of the analysis were used to calculate the total recovery (\%) and the average recovery (\%) of DEHA form the sample matrix.

\section{Results}

\section{HPTLC and refinement results}

The chromatographic spots of Sample A, Sample B, the DEHA standard solutions and blank solution, as well as the individual $\mathrm{Rf}$, three-dimensional figure and the peak spectrodensitometric analysis curves are shown in Fig. 1.

\section{Quantification results}

The linear relationship between DEHA concentration and spot peaks areas for the standards can be expressed as:
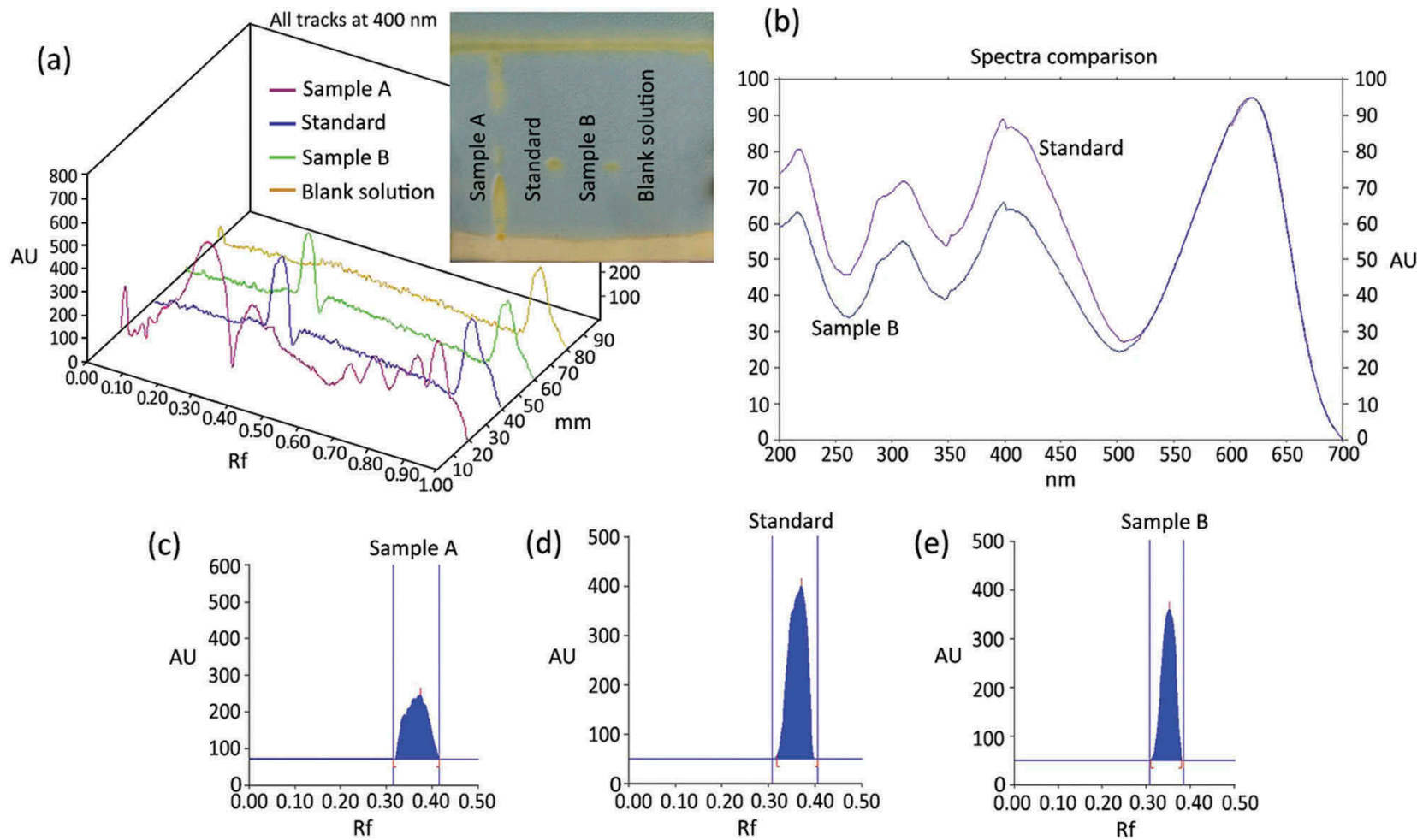

Figure 1. (a) The HPTLC plate after the staining process and the three-dimensional analysis of Sample A, the DEHA standard, Sample B and the blank solution. The spectral densitometric analysis of (b) Sample B and the DHEA standard and densitometric peaks for (c) Sample A, (d) the DEHA standard and (e) Sample B at an Rf of 0.36. 
Table 1. Average peak areas corresponding to different amounts of DEHA.

\begin{tabular}{lccc}
\hline Spot & Volume $(\mu \mathrm{L})$ & DEHA $(\mu \mathrm{g})$ & Average peak areas $(\mathrm{AU})$ \\
\hline Standard 1 & 1 & 1 & 2843.12 \\
Standard 2 & 2 & 2 & 4447.07 \\
Standard 3 & 3 & 3 & 6041.82 \\
Standard 4 & 3.5 & 3.5 & 6904.96 \\
Standard 5 & 4 & 4 & 7510.64 \\
Sample & 3 & 1.39 & 3487.10 \\
\hline
\end{tabular}

Table 2. Intraplate variation and interplate variation of the HPTLC analysis.

\begin{tabular}{lccccc}
\hline & \multicolumn{2}{c}{ Intraplate variation } & & \multicolumn{2}{c}{ Interplate variation } \\
\cline { 2 - 3 } \cline { 5 - 6 } Spot & Peak area & RSD (\%) & & Peak area & RSD (\%) \\
\hline 1 & 4404.6 & 1.03 & & 4474.2 & 1.56 \\
2 & 4493.8 & & 4543.3 & \\
3 & 4488.5 & & 4448.7 & \\
4 & 4397.7 & & 4480.1 & \\
5 & 4429.4 & & 4351.4 & \\
\hline
\end{tabular}

Table 3. Stability of DEHA-chromogen based on peak area analysis after staining.

\begin{tabular}{lccc}
\hline $\begin{array}{l}\text { Time after } \\
\text { staining }\end{array}$ & $\begin{array}{c}\text { Area of spot 1 } \\
\text { (AU) }\end{array}$ & $\begin{array}{c}\text { Area of spot 2 } \\
(\mathrm{AU})\end{array}$ & $\begin{array}{c}\text { Area of spot 3 } \\
\text { (AU) }\end{array}$ \\
\hline $0 \mathrm{~h}$ & 5646.5 & 5690.6 & 5731.8 \\
$1 \mathrm{~h}$ & 5615.8 & 5683.1 & 5708.0 \\
$2 \mathrm{~h}$ & 5571.6 & 5594.5 & 5627.3 \\
$3 \mathrm{~h}$ & 5094.1 & 5116.2 & 5014.8 \\
RSD $(0-2 \mathrm{~h}) \%$ & 0.67 & 0.95 & 0.96 \\
RSD $(0-3 \mathrm{~h}) \%$ & 4.75 & 4.95 & 6.16 \\
\hline
\end{tabular}

of sensitivity should allow for detecting and quantifying DEHA in many different types of matrices.

\section{Extraction and detection results for DEHA in Antarctic krill oil}

Employing the described methods, the concentration of DEHA in the Antarctic krill oil was calculated to be ca. $2.16 \pm 0.08 \mathrm{mg} / \mathrm{g}(\mathrm{n}=3)$.

\section{GC-MS analytical results}

The results of the GC-MS analysis of Sample B and the DEHA standards are shown in Fig. 2. This result proved the presence of DEHA in Sample B.

\section{FTIR results for Sample B and the DEHA standard}

The FTIR spectra for Sample B and the DEHA standard are shown in Fig. 3. The two spectra were very similar, indicating that Sample B contained DEHA.

\section{Repetition and recovery results}

The results for the test repetition are shown in Table 4, where the DEHA concentration of the dry Antarctic krill was calculated to be $0.63 \pm 0.05 \mathrm{mg} / \mathrm{g}$. The results for the recovery tests are shown in Table 5 and the average percentage recovery of DEHA at three different levels was $97.3 \%$ with an RSD of $2.47-4.90 \%$.

\section{Discussion}

In this study, we extracted DEHA in Antarctic krill with anhydrous ethanol by an ultrasound method with the aim of reducing solvents and pollution. As a method to detect DEHA, GC-MS demands complicated operation and purification procedures. The HPLC method also needs complex pretreatment and consumes much solvents. Because of its low operation cost, simple pretreatment, lower solvent use, good accuracy and high sample throughput (Rezić et al. 2005), HPTLC is potentially an excellent method for detecting DEHA. This was demonstrated in our study, in which we detected and quantified DEHA in Antarctic krill using an HPTLC analysis. In this method, a new developing solvent and chromogenic agent were employed. Validation tests (according to International Council for Harmonisation of Technical Requirements for Registration of Pharmaceuticals for Human Use guidelines) confirmed the utility of this method as a way to detect and quantify DEHA, especially in Antarctic krill (Human Medicines Evaluation Unit 1994).

This is the first report concerning the presence of DEHA in Antarctic krill. The content of DEHA in the freeze-dried Antarctic krill that we tested was $0.63 \pm 0.05 \mathrm{mg} / \mathrm{g}(630 \pm 50 \mathrm{mg} / \mathrm{kg})$. The content of DEHA in Antarctic krill oil using the described

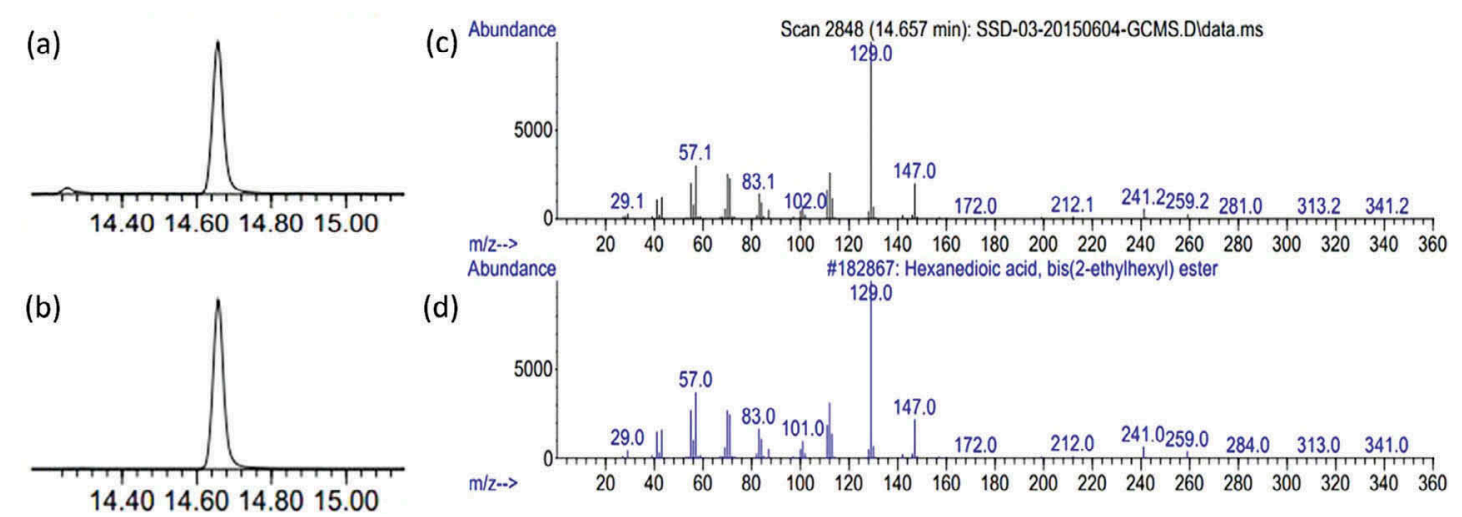

Figure 2. Retention time (a) of Sample B and (b) the DEHA standard, and mass spectra of (c) Sample B and (d) the DEHA standard. 


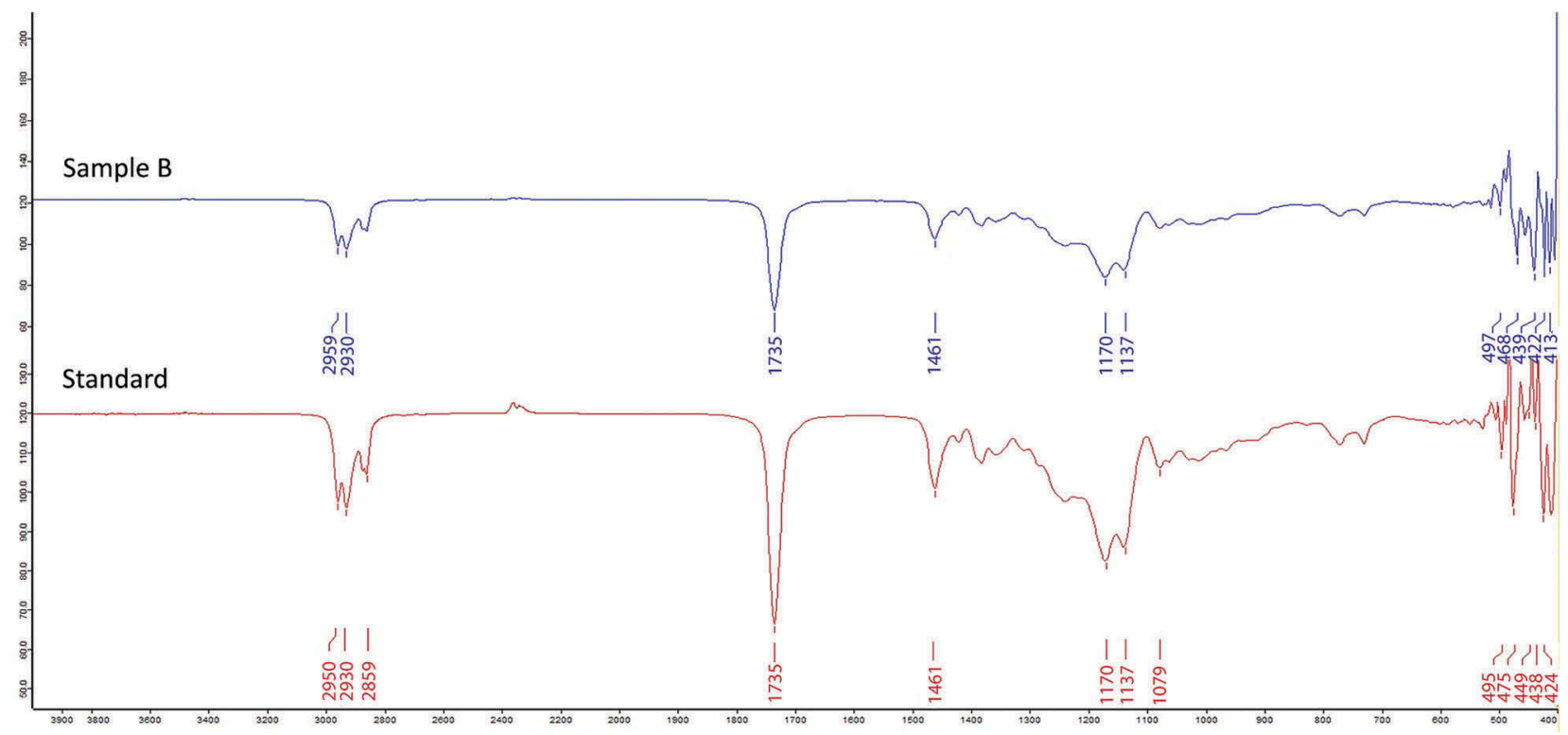

Figure 3. FTIR spectra of Sample B and the DEHA standard.

Table 4. DEHA concentration for repeated sampling of freeze-dried Antarctic krill.

\begin{tabular}{lccccccccc}
\hline & Sample 1 & Sample 2 & Sample 3 & Sample 4 & Sample 5 & Sample 6 & Sample 7 & Sample 8 & Mean \pm SD \\
\hline DEHA $(\mu \mathrm{g} / \mu \mathrm{L})$ in refined sample (Sample B) & 0.463 & 0.520 & 0.487 & 0.514 & 0.445 & 0.584 & 0.516 & 0.474 & $0.500 \pm 0.04$ \\
DEHA $(\mathrm{mg} / \mathrm{g})$ in Antarctic krill & 0.58 & 0.65 & 0.61 & 0.64 & 0.56 & 0.73 & 0.65 & 0.59 & $0.63 \pm 0.05$ \\
\hline
\end{tabular}

Table 5. DEHA recovery determination.

\begin{tabular}{lccccc}
\hline & $\begin{array}{c}\text { Amount of } \\
\text { standard } \\
\text { added } \\
\text { Compound }\end{array}$ & $\begin{array}{c}\text { Amount of } \\
\text { standard } \\
\text { determined } \\
(\mathrm{mg})\end{array}$ & $\begin{array}{c}\text { Recovery } \\
(\%)\end{array}$ & $\begin{array}{c}\text { Mean } \\
\text { recovery } \\
(\%)\end{array}$ & $\begin{array}{c}\text { RSD } \\
(\%)\end{array}$ \\
\hline \multirow{3}{*}{ DEHA } & 1.25 & $1.27 \pm 0.060$ & $101.6 \%$ & & $4.72 \%$ \\
& 2.50 & $2.33 \pm 0.114$ & $93.2 \%$ & $97.3 \%$ & $4.90 \%$ \\
& 3.75 & $3.64 \pm 0.090$ & $97.1 \%$ & & $2.47 \%$ \\
\hline
\end{tabular}

method was found to be $2.16 \pm 0.08 \mathrm{mg} / \mathrm{g}$ $(2160 \pm 80 \mathrm{mg} / \mathrm{kg})$. The structure of the DEHA found in the Antarctic krill as determined by GCMS and IR confirmed its presence. GC-MS further validated the feasibility of using HPTLC as a method for determining DEHA.

As shown in Table 6, DEHA can have negative effects on a wide variety of organisms. The highest and lowest concentrations that can affect organisms are $1000 \mathrm{mg} / \mathrm{kg}$ and $0.087 \mathrm{mg} / \mathrm{L}$. The concentration of DEHA in dry Antarctic krill was found to be $630 \pm 50 \mathrm{mg} / \mathrm{kg}(126 \mathrm{mg} / \mathrm{kg}$ in fresh Antarctic krill according to $80 \%$ water content), which is very high. Although the effects of DEHA on Antarctic krill have not been defined, based on the known effects of this contaminant on other species, it is reasonable to assume that DEHA may harm Antarctic krill at the high concentrations determined in this study. The accumulation of DEHA in krill could lead to the poisoning of other animals in this food chain, seriously affecting the Antarctic ecosystem. As people consume krill-based products, it could also seriously affect human health.
There are no detailed data on the sources and concentrations of DEHA in Antarctic biota. DEHA may be entering Antarctic krill through several pathways. The natural concentration of DEHA in water is $0.78 \pm 0.16 \mathrm{mg} / \mathrm{L}$ (Felder et al. 1986), which is quite low, but there has been little research dealing with the concentration of DEHA in the Southern Ocean, so whether Antarctic krill absorb DEHA from seawater is not known. One study showed that algae can produce DEHA internally in high concentrations (Bi et al. 2016). Consequently, Antarctic krill may ingest DEHA directly by consuming these algae as food.

The presence of DEHA in the Antarctic marine ecosystem may result primarily from plastic pollution. It has been shown that Antarctic waters are contaminated with plastic particles (Fendall \& Sewell 2009), which marine organisms readily absorb. The main route by which krill are contaminated by DEHA may therefore be direct absorption of large quantities of plastic particles. The global production of plastics is around 300 million metric tonnes annually, much of which eventually finds its way to the sea (Brink et al. 2017). The plastic garbage directly discarded by humans in the Antarctic may also be a source of DEHA as human Antarctic activities continues to increase (Stark et al. 2006).

DEHA may move to the Antarctic by long-range atmospheric and hydrospheric transport. Migratory species (such as seabirds) may bio-transport DEHA 
Table 6. Harmful effects of DEHA on organisms and their related concentrations.

\begin{tabular}{|c|c|c|c|}
\hline Species & Concentration & Harmful effects on organisms & Reference \\
\hline \multicolumn{4}{|l|}{ Algae } \\
\hline Heterosigma akashiwo & $5.82 \mathrm{mg} / \mathrm{L}$ & Strongly inhibiting growth & Bi et al. (2016) \\
\hline Gymnodinium breve & $2.74 \mathrm{mg} / \mathrm{L}$ & Strongly inhibiting growth & Bi et al. (2016) \\
\hline \multicolumn{4}{|l|}{ Zooplankton } \\
\hline Daphnia magna & $\begin{array}{l}0.087 \mathrm{mg} / \mathrm{L} \\
\text { and } \\
0.180 \mathrm{mg} / \mathrm{L}\end{array}$ & Notable effect on survival; notable effect on growth & Felder et al. (1986) \\
\hline \multicolumn{4}{|l|}{ Fishes } \\
\hline Sparus aurata (sea bream) & 250 ppm & $\begin{array}{c}\text { Notable changes of gill histopathological indices; liver hepatocellular } \\
\text { changes (steatosis, necrosis and fibrosis) }\end{array}$ & Üreten \& Üçüncü (2013) \\
\hline $\begin{array}{l}\text { Labidochromis caeruleus } \\
\text { (yellow princess) }\end{array}$ & $0.75 \mathrm{ppm}$ & $\begin{array}{c}\text { Notable changes of gill histopathological indices (hypertropy, severe } \\
\text { hyperplasia, aneurysma, oedema, lifting epithelial and striking } \\
\text { fusion) }\end{array}$ & Ücüncü et al. (2010) \\
\hline \multicolumn{4}{|l|}{ Mammals } \\
\hline Female F344 rats & $0 \%-4 \%$ & $\begin{array}{c}\text { Dose-dependent increase in liver weight; dose-dependent increase in } \\
\text { hepatic peroxisome proliferation }\end{array}$ & Lake et al. (1997) \\
\hline \multirow[t]{2}{*}{ Female B6C3F1 mice } & $0 \%-2.5 \%$ & $\begin{array}{c}\text { Dose-dependent increase in liver weight; dose-dependent increase in } \\
\text { hepatic peroxisome proliferation }\end{array}$ & Lake et al. (1997) \\
\hline & $\begin{array}{c}1.2 \% \text { and } \\
2.5 \%\end{array}$ & Sustained stimulation of replicative DNA synthesis & \\
\hline \multirow[t]{3}{*}{ Wistar rats } & $800 \mathrm{mg} / \mathrm{kg}$ & Prolonged gestation period & Dalgaard et al. (2003) \\
\hline & $400 \mathrm{mg} / \mathrm{kg}$ & Dose-dependent increase in postnatal death & \\
\hline & $800 \mathrm{mg} / \mathrm{kg}$ & Permanent decrease in offspring body weight & \\
\hline F344 rats & $2.5 \%$ & $\begin{array}{c}\text { Increase in 8-OH-Dg levels in liver oxidative DNA damage } \\
\text { hepatocarcinogenesis }\end{array}$ & Takagi et al. (1990) \\
\hline Male rats & $0.5 \%$ & $\begin{array}{c}\text { Inhibition hepatic cholesterolgenesis and modification of phospholipid } \\
\text { synthesis in liver }\end{array}$ & Bell (1983) \\
\hline & $1 \%$ & Cholesterol-lowering effect & \\
\hline Rats & $1000 \mathrm{mg} / \mathrm{kg}$ & $\begin{array}{c}\text { Disturbed estrous cycle; increased ovarian follicle atresia; adrenal } \\
\text { weight decrease }\end{array}$ & Miyata et al. (2006) \\
\hline
\end{tabular}

into the Antarctic from food chains elsewhere. Determining the sources of DEHA in Antarctic requires further research.

Fresh Antarctic krill, Antarctic krill powder and Antarctic krill oil are the main krill products. These products are exported and widely consumed throughout the world. The tolerable daily intake of DEHA by humans is $0.3 \mathrm{mg} / \mathrm{kg}$ bw/day (Fromme et al. 2013). The concentration of DEHA that we found in freeze-dried Antarctic krill is significantly higher, and the content of DEHA in Antarctic krill oil was even higher. DEHA in krill is a serious concern in human food consumption.

DEHA may present a growing threat to the survival and reproduction of Antarctic krill, which is an important part of the food web in the Southern Ocean. The adverse effects of DEHA on Antarctic krill and the source of DEHA in the Antarctic should be explored in future research.

\section{Acknowledgements}

The experimental raw materials were supplied by the Liaoning Fishery Group.

\section{Compliance with ethical standards}

This study was approved by the Shandong Institute of Zoology and followed all applicable international, national and/or institutional guidelines for the care and use of animals.

\section{Disclosure statement}

No potential conflict of interest was reported by the authors.

\section{Funding}

This study was funded by the Shandong Key R \& D Plan (key scientific and technological project; grant no. gg10002088).

\section{References}

Abdul Rahman M.B., Chaibakhsh N., Basri M., Salleh A.B. \& Abdul Rahman R.N.Z.R. 2009. Application of artificial neural network for yield prediction of lipase-catalyzed synthesis of dioctyl adipate. Applied Biochemistry \& Biotechnology 158, 722-735.

Ali-Nehari A., Kim S.B., Lee Y.B., Lee H.Y. \& Chun B.S. 2012. Characterization of oil including astaxanthin extracted from krill (Euphausia superba) using supercritical carbon dioxide and organic solvent as comparative method. Korean Journal of Chemical Engineering 29, 329-336.

Badeka A.B., Pappa K. \& Kontominas M.G. 1999. Effect of microwave versus conventional heating on the migration of dioctyl adipate and acetyltributyl citrate plasticizers from food grade PVC and P (VDC/VC) films into fatty foodstuffs. Zeitschrift Für Lebensmitteluntersuchung und -Forschung A 208, 429-433.

Bell F.P. 1983. Effect of the plasticizer di(2-ethylhexyl) adipate (dioctyladipate, DOA) on lipid metabolism in the rat: I. Inhibition of cholesterolgenesis and modification of phospholipid synthesis. Lipids 18, 211-215. 
Bi X.D., Dong S.J., Xu D.W., Guo Y.J. \& Li Y.G. 2016. One kind of allelochemicals against algae and extraction and purification method. Chinese patent number $\mathrm{CN}$ $104782626 \mathrm{~B}[\mathrm{P}]$.

Brink P.T., Schweitzer J.P., Watkins E., Smet M.D., Leslie H. \& Galgani F. 2017. Circular economy measures to keep plastics and their value in the economy, avoid waste and reduce marine litter. Paper presented at G20 Germany 2017, Think 20 Dialogue, 28-30 May, Berlin.

Dalgaard M., Hass U., Vinggaard A.M., Jarfelt K., Lam H. R., Sørensen I.K., Sommer H.M. \& Ladefoged O. 2003. Di(2-ethylhexyl) adipate (DEHA) induced developmental toxicity but not antiandrogenic effects in pre- and postnatally exposed Wistar rats. Reproductive Toxicology 17, 163-170.

Di Bella G., Potortì A.G., Lo Turco V., Saitta M. \& Dugo G. 2014. Plasticizer residues by HRGC-MS in espresso coffees from capsules, pods and moka pots. Food Control 41, 185-192.

Felder J.D., Adams W.J. \& Saeger V.W. 1986. Assessment of the safety of dioctyl adipate in freshwater environments. Environmental Toxicology \& Chemistry 5, 777-784.

Fendall L.S. \& Sewell M.A. 2009. Contributing to marine pollution by washing your face: microplastics in facial cleansers. Marine Pollution Bulletin 58, 1225-1228.

Fosshaug L.E., Berge R.K., Beitnes J.O., Berge K., Vik H., Aukrust P., Gullestad L., Vinge L.E. \& Øie E. 2011. Krill oil attenuates left ventricular dilatation after myocardial infarction in rats. Lipids in Health and Disease 10, 245-254.

Fromme H., Gruber L., Schuster R., Schlummer M., Kiranoglu M., Bolte G. \& Völkel W. 2013. Phthalate and di-(2-ethylhexyl) adipate (DEHA) intake by German infants based on the results of a duplicate diet study and biomonitoring data (INES 2). Food \& Chemical Toxicology 53, 272-280.

Gigliotti J.C., Davenport M.P., Beamer S.K., Tou J.C. \& Jaczynski J. 2011. Extraction and characterisation of lipids from Antarctic krill (Euphausia superba). Food Chemistry 125, 1028-1036.

He L., Lin Q.B. \& Tian H.J. 2013. Simultaneous determination of 16 plasticizers and 7 antioxidants in vinegar by GC-MS. Food Science 34, 143-148.

Human Medicines Evaluation Unit. 1994. Note for guidance on validation of analytical methods: definitions and terminology. CPMP/ICH/381/95. London: Human Medicines Evaluation Unit, European Agency for the Evaluation of Medicinal Products.

Kokubun N., Choy E.J., Kim J.H. \& Takahashi A. 2015. Isotopic values of Antarctic krill in relation to foraging habitat of penguins. Ornithologicalence 14, 13-20.

Lake B.G., Price R.J., Cunninghame M.E. \& Walters D.J. 1997. Comparison of the effects of di-(2-ethylhexyl) adipate on hepatic peroxisome proliferation and cell replication in the rat and mouse. Toxicology 123, 217-226.

Li B., Wang Z.W., Lin Q.B. \& Hu C.Y. 2016. Study of the migration of stabilizer and plasticizer from polyethylene terephthalate into food simulants. Journal of Chromatographic Science 54, 939-951.
Lo Turco V., Di Bella G., Potortì A.G., Fede M.R. \& Dugo G. 2015. Determination of plasticizer residues in tea by solid phase extraction-gas chromatography-mass spectrometry. European Food Research \& Technology 240, 451-458.

Maki K.C., Reeves M.S., Farmer M., Griinari M., Berge K., Vik H., Hubacher R. \& Rains T.M. 2009. Krill oil supplementation increases plasma concentrations of eicosapentaenoic and docosahexaenoic acids in overweight and obese men and women. Nutrition Research 29, 609-615.

Miyata K., Shiraishi K., Houshuyama S., Imatanaka N., Umano T., Minobe Y. \& Yamasaki K. 2006. Subacute oral toxicity study of di(2-ethylhexyl) adipate based on the draft protocol for the "Enhanced OECD Test Guideline no. 407". Archives of Toxicology 80, 10-16.

Qian X.Z., Xiang Y.L., Shang H.F., Cheng B.X., Zhan S.P. \& Jian L.I. 2016. Thermal-oxidation mechanism of dioctyl adipate base oil. Friction 4, 29-38.

Rahman M. \& Brazel C.S. 2004. The plasticizer market: an assessment of traditional plasticizers and research trends to meet new challenges. Progress in Polymer Science 29, 1223-1248.

Rezić I., Horvat A.J., Babić S. \& Kaštelan-Macan M. 2005. Determination of pesticides in honey by ultrasonic solvent extraction and thin-layer chromatography. Ultrasonics Sonochemistry 12, 477-481.

Stark J.S., Snape I. \& Riddle M.J. 2006. Abandoned Antarctic waste disposal sites: monitoring remediation outcomes and limitations at Casey Station. Ecological Management \& Restoration 7, 21-31.

Takagi A., Sai K., Umemura K., Hasegawa R. \& Kurokawa Y. 1990. Significant increase of 8-Hydroxydeoxyguanosine in liver DNA of rats following short-term exposure to the peroxisome proliferators di(2-ethylhexyl) phthalate and di(2-ethylhexyl) adipate. Cancer Science 81, 213-215.

Ücüncü S.I., Ergen G., Önen Ö., Tekkan B.K., Üreten M., Boz E., Seferoğlu K. \& Gökçe B. 2010. Dioktil adipat'ın (DOA) Labidochromis caeruleus Fryer, 1956 (Cichlidae, Teleostei) karaciğer histolojisi üzerindeki etkileri. (The effects of dioctyl adipate [DOA] on the liver histology of Labidochromis caeruleus Fryer, 1956 [Cichlidae, Teleostei].) Kafkas Üniversitesi Veteriner Fakültesi Dergisi 16, S197-S203, doi: 10.9775/kvfd.2009.1132.

Üreten M. \& Üçüncü S.İ. 2013. Dioktil adipat (DOA) 'ın Sparus aurata (Çipura) karaciğer ve solungaç histolojisi üzerine etkileri. (The effects of dioctyl adipate [DOA] on liver and gill histology of Sparus aurata [sea bream].) Ege University Faculty of Fisheries 30, 115-122.

Wang F.J. 1996. Determination of dioctyl adipate in plasticizer - indirect ultraviolet photometric HPLC. Journal of Petrochemical Universities of Sinopec 9, 31-33.

Wibrand K., Berge K., Messaoudi M., Duffaud A., Panja D., Bramham C.R. \& Burri L. 2013. Enhanced cognitive function and antidepressant-like effects after krill oil supplementation in rats. Lipids in Health \& Disease 12, 6-35.

Yavan N. 1984. Final report on the safety assessment of dioctyl adipate and diisopropyl adipate. International Journal of Toxicology 3, 101-130. 